\title{
Capability of multi-viewing-angle photo-polarimetric measurements for the simultaneous retrieval of aerosol and cloud properties
}

\author{
O. P. Hasekamp \\ SRON, Netherlands Institute for Space Research, Sorbonnelaan 2, 3584 CA Utrecht, The Netherlands
}

Received: 26 February 2010 - Published in Atmos. Meas. Tech. Discuss.: 25 March 2010

Revised: 10 June 2010 - Accepted: 22 June 2010 - Published: 6 July 2010

\begin{abstract}
An important new challenge in the field of multiangle photo-polarimetric satellite remote sensing is the retrieval of aerosol properties under cloudy conditions. In this paper the possibility has been explored to perform a simultaneous retrieval of aerosol and cloud properties for partly cloudy scenes and for fully cloudy scenes where the aerosol layer is located above the cloud, using multi-angle photopolarimetric measurements. Also, for clear sky conditions a review is given of the capabilities of multi-angle photopolarimetric measurements in comparison with other measurement types. It is shown that already for clear sky conditions polarization measurements are highly important for the retrieval of aerosol optical and microphysical properties over land surfaces with unknown reflection properties. Furthermore, it is shown that multi-angle photo-polarimetric measurements have the capability to distinguish between aerosols and clouds, and thus facilitate a simultaneous retrieval of aerosol and cloud properties. High accuracy (0.002-0.004) of the polarimetric measurements plays an essential role here.
\end{abstract}

\section{Introduction}

Anthropogenic aerosols are believed to cause the second most important anthropogenic forcing of climate change after greenhouse gases. In contrast to the climate effect of greenhouse gases, which is understood relatively well, the negative forcing (cooling effect) caused by aerosols represents the largest reported uncertainty in the most recent assessment of the International Panel on Climate Change

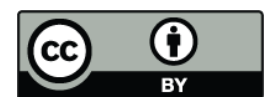

Correspondence to: O. P. Hasekamp (o.hasekamp@sron.nl)
(Solomon, 2007). This uncertainty severely hampers future predictions of climate change. Strong aerosol cooling in the past and present would imply that future global warming may proceed at or even above the upper extreme of the range projected by the IPCC (Andrea et al., 2005). Aerosols can affect the climate system via several mechanisms: 1) the reflection of solar radiation back to space (direct effect), 2) the absorption of solar radiation by soot and mineral dust to warm the atmospheric aerosol layer, which could hinder cloud formation and cause cloud droplets to evaporate (semi-direct effect, Koren et al., 2004), and 3) the capability to act as condensation nuclei for clouds (indirect effects). The latter (indirect) effect can be distinguished into a cloud albedo effect (Twomey, 1959) and a cloud lifetime effect (Albrecht, 1989). The aerosol effects related to clouds (semi-direct and indirect) are considered as the largest yet most uncertain aerosol effects (Lohmann and Feichter, 2005).

The large uncertainty on the aerosol effects on clouds and climate is reflected in considerable discrepancies between different model simulations of the radiative forcing caused by these effects. Also, there exist large differences between values for radiative forcing calculated by models and those estimated from satellite measurements, and model calculations constrained by satellite measurements (Bréon et al., 2002; Quaas and Boucher, 2005; Quaas et al., 2008). Relationships between aerosols and clouds derived from satellite measurements are subject to a number of important limitations. First of all, with current satellite aerosol products it is hard to determine which fraction of the aerosols is anthropogenic and which fraction is natural. Often the rather crude assumption is used that the fine mode contribution is fully anthropogenic. Furthermore, most aerosol types are strongly hygroscopic, which means that in an environment with high relative humidity (in the neighborhood of clouds) the particle size

Published by Copernicus Publications on behalf of the European Geosciences Union. 
increases considerably leading in turn to an increase in optical thickness (Kotchenruther et al., 1999). This effect may be misinterpreted as an apparent relation between aerosol concentration and cloud cover. Also meteorology effects can be misinterpreted as apparent aerosol-cloud relationships. Accurate information on aerosol size and refractive index (related to chemical composition of aerosols and absorption) is needed to distinguish between natural and anthropogenic aerosols and to distinguish between aerosol effects on cloud formation and apparent relationships due to humidity and meteorology effects. Another problem with current satellite aerosol products is that they are affected by residual cloud contamination due to imperfect cloud screening. Therefore, a type of satellite measurements is needed that allows to distinguish between aerosols and residual cloud contamination. Related to that, also aerosol measurements above low clouds are needed to quantify the semi-direct effect.

Many satellite instruments that are used for aerosol retrieval are multiple-wavelength single-viewing-angle instruments. Among these instruments are the Advanced Very High Resolution Radiometer (AVHRR), the Moderate Resolution Imaging Spectroradiometer (MODIS), the Total Ozone Mapping Spectrometer (TOMS), the Global Ozone Monitoring Experiment (GOME) and the Scanning Imaging Absorption Spectrometer for Atmospheric Chartography (SCIAMACHY). Although it has been shown that the aerosol optical thickness may be retrieved from these instruments (Tanré et al., 1999; Mishchenko et al., 1999; Torres et al., 2001; Remer et al., 2005; Veefkind et al., 2000), the results depend critically on the assumed values of the other aerosol parameters (size distribution, refractive index). The aerosol information content of intensity measurements is significantly larger for instruments that perform measurements at multiple viewing angles, such as the Multiangle Imaging Spectro-Radiometer (MISR, Diner et al., 2005), and the Advanced Along-Track Scanning Radiometer (AATSR). However, the combined use of intensity and polarization measurements at multiple viewing angles have been shown to be by far the most powerful for the purpose of aerosol retrieval (Mishchenko and Travis, 1997a,b; Chowdhary et al., 2001; Hasekamp and Landgraf, 2007; Waquet et al., 2009a). The reason for this is the high sensitivity of polarization properties of light to aerosol micro-physics (Hansen and Travis, 1974). Satellite measurements of intensity and polarization at 14 viewing angles in the spectral range 443$865 \mathrm{~nm}$ have been performed by two versions of the Polarization and Directionality of Earth's Reflectances instruments (POLDER). Both instruments were active for about 8 months in 1996/1997 and 2002, respectively. Since the end of 2004 the POLDER-2 instrument, which is a somewhat adjusted version of POLDER, is in orbit on the PARASOL satellite. Aerosol retrievals from POLDER have been reported, among others, by Deuzé et al. (2000, 2001) and Herman et al. (2005). The Aerosol Polarimetry Sensor (APS) (Mishchenko et al., 2004) to be launched 2010 will perform multiple-viewing-angle measurements of intensity and polarization at a higher accuracy (0.002 instead of 0.01-0.02) in a broader spectral range (410-2250 nm instead of 443$1013 \mathrm{~nm}$ ), and at more viewing angles (260 instead of 14) than POLDER/PARASOL. The capabilities of APS for the retrieval of aerosol properties have been demonstrated using airborne measurements of the Research Scanning Polarimeter (RSP), which is functionally similar to APS, by e.g. Chowdhary et al. (2001, 2002, 2005); Waquet et al. (2009a).

A new challenge in the field of multi-angle photopolarimetric satellite remote sensing is the retrieval of aerosol properties under cloudy conditions. This includes scenes with an aerosol layer located below a broken cloud field and scenes with an aerosol layer above a low level homogeneous cloud field. Waquet et al. (2009b) demonstrated the capability of PARASOL polarimetric measurements to retrieve Aerosol Optical Thickness (AOT) under the latter condition. Their retrieval is based on a number of pre-described aerosol size distributions and a fixed refractive index representative for their specific case study. Important next steps to be taken by retrieval schemes for APS (with higher polarimetric accuracy, extended spectral range, improved angular resolution) are to simultaneously retrieve aerosol and cloud properties, extend the retrieval to partly clouded conditions, and to extend the retrieval to microphysical properties such as size and refractive index.

The aim of this paper is to explore the possibilities to perform a simultaneous retrieval of aerosol and cloud properties for situations with an aerosol layer located below a broken cloud field, and for situations with an elevated aerosol layer above a homogeneous low level cloud field. Furthermore, for clear sky conditions a review is given of the capabilities of multi-angle photopolarimetric measurements in comparison to other instrument types, extending the analysis of Hasekamp and Landgraf (2007). Section 2 discusses scattering properties of aerosols and clouds, and Sect. 3 describes the retrieval method and forward model. The capabilities of different measurement types with respect to aerosol retrieval under clear sky conditions are described in Sect. 4, whereas in Sect. 5 the possibilities of simultaneously retrieving aerosol and cloud properties from multi-angle photopolarimetric measurements are investigated. Finally, Sect. 6 concludes the paper.

\section{Theory}

The radiance and state of polarization of light at a given wavelength can be described by an intensity vector $\boldsymbol{I}$ which has the Stokes parameters as its components (Chandrasekhar, 1960):

$\boldsymbol{I}=[I, Q, U, V]^{\mathrm{T}}$, 
Table 1. Aerosol/cloud types used to create synthetic measurements of intensity and polarization. The aerosol types "European Background" and "European Polluted" are taken from a model run of the ECHAM5-HAM aerosol model (Stier et al., 2005). The "Biomass Burning" and "Coarse spherical" aerosol types are taken from Torres et al. (2001) (where "Coarse spherical" is called "Dust"). $r_{\text {eff }}$ refers to effective radius, $v_{\text {eff }}$, to effective variance, $m_{\mathrm{r}}$ and $m_{\mathrm{i}}$ to the real and imaginary part of the refractive index, respectively, $\tau_{550}$ to the aerosol optical thickness at $550 \mathrm{~nm}$. Further, the superscripts "s" and "l" refer to the small and large mode, respectively.

\begin{tabular}{|c|c|c|c|c|c|c|c|c|c|}
\hline Type & $r_{\mathrm{eff}}^{\mathrm{s}}(\mu \mathrm{m})$ & $v_{\mathrm{eff}}^{\mathrm{s}}$ & $r_{\mathrm{eff}}^{1}(\mu \mathrm{m})$ & $v_{\mathrm{eff}}^{1}$ & $\tau_{550}^{1} / \tau_{550}^{\text {tot }}$ & $m_{\mathrm{r}}^{\mathrm{s}}$ & $m_{\mathrm{i}}^{\mathrm{s}}$ & $m_{\mathrm{r}}^{1}$ & $m_{\mathrm{i}}^{1}$ \\
\hline $\begin{array}{l}\text { European } \\
\text { Background }\end{array}$ & 0.222 & 0.246 & 1.592 & 0.616 & 0.4 & 1.35 & -0.0022 & 1.38 & -0.00022 \\
\hline $\begin{array}{l}\text { Biomass } \\
\text { Burning }\end{array}$ & 0.119 & 0.174 & 2.671 & 0.704 & 0.078 & 1.50 & -0.02 & 1.50 & -0.02 \\
\hline $\begin{array}{l}\text { Coarse spherical } \\
\text { Cloud }\end{array}$ & $\begin{array}{c}0.105 \\
\mathrm{n} / \mathrm{a}\end{array}$ & $\begin{array}{c}0.323 \\
\mathrm{n} / \mathrm{a}\end{array}$ & $\begin{array}{c}1.605 \\
6.0\end{array}$ & $\begin{array}{c}0.418 \\
0.11\end{array}$ & $\begin{array}{c}0.74 \\
1.0\end{array}$ & $\begin{array}{c}1.53 \\
\mathrm{n} / \mathrm{a}\end{array}$ & $\begin{array}{c}-0.0055 \\
\mathrm{n} / \mathrm{a}\end{array}$ & $\begin{array}{l}1.53 \\
1.33\end{array}$ & $\begin{array}{l}-0.0055 \\
0.0\end{array}$ \\
\hline
\end{tabular}

where $\mathrm{T}$ indicates the transposed vector, and the Stokes parameters are defined with respect to a certain reference plane. The angular dependence of single scattering of polarized light can be described by means of the scattering phase matrix $\mathbf{P}$. Here, only scattering phase matrices of the following form are considered:

$\mathbf{P}(\theta)=\left(\begin{array}{cccc}p_{1}(\theta) & p_{5}(\theta) & 0 & 0 \\ p_{5}(\theta) & p_{2}(\theta) & 0 & 0 \\ 0 & 0 & p_{3}(\theta) & p_{6}(\theta) \\ 0 & 0 & -p_{6}(\theta) & p_{4}(\theta)\end{array}\right)$.

where $p_{1}, p_{2}, \ldots, p_{6}$ are certain functions of scattering angle $\theta$ and the scattering plane is the plane of reference. This type of scattering matrix is valid for (van de Hulst, 1957) (i) scattering by an assembly of randomly oriented particles each having a plane of symmetry, (ii) scattering by an assembly containing particles and their mirror particles in equal numbers and with random orientations, (iii) Rayleigh scattering with or without depolarization effects.

Figure 1 shows phase function (element $p_{1}$ ) and the signed degree of linear polarization $\left(-p_{5} / p_{1}\right)$ for a biomass burning aerosol type, a coarse spherical aerosol type, and cloud droplets (see Table 1), calculated using Mie theory. It can be seen that both the spectral dependence and the angular dependence of the phase function and signed degree of linear polarization are very different for the two aerosol types. Also, if we compare the scattering characteristics of cloud droplets with aerosols, it can be seen that element $p_{1}$ of cloud droplets is very different to $p_{1}$ of biomass aerosols. The difference in $p_{1}$ between cloud droplets and coarse spherical aerosols is still present but less pronounced. The signed degree of linear polarization of cloud droplets is very distinct from that of either aerosol type. Figure 1 indicates that the spectral- and angular behavior of the total intensity and polarization of backscattered light contains important information on aerosol properties. Furthermore, in particular the angular dependence of the signed degree of polarization may be expected to provide the information to distinguish between aerosols and clouds. For a detailed discussion on the physi- cal background of the sensitivity of intensity and polarization to particle characteristics the reader is referred to the work of Hansen and Travis (1974) and Mishchenko et al. (2006).

\section{Retrieval method}

\subsection{Aerosol, cloud, and surface properties}

For all simulations in this paper it is assumed that the aerosol size distribution is bi-modal, where the size distribution $n$ for each mode is given by a log-normal function

$n(r)=\frac{1}{\sqrt{2 \pi} \sigma_{g} r} \exp \left[-\left(\ln r-\ln r_{g}\right)^{2} /\left(2 \sigma_{g}^{2}\right)\right]$,

where $r$ describes particle radius (or radius of a volume equivalent sphere),

$\ln r_{g}=\int_{0}^{\infty} \ln r n(r) d r$

and

$\sigma_{g}^{2}=\int_{0}^{\infty}\left(\ln r-\ln r_{g}\right)^{2} n(r) d r$.

As shown by Hansen and Travis (1974) it is useful to characterize (a mode of) the size distribution by the effective radius $r_{\text {eff }}$ and effective variance $v_{\text {eff }}$, because these parameters are relatively independent from the actual shape of the distribution. Here,

$r_{\mathrm{eff}}=\frac{\int_{0}^{\infty} r \pi r^{2} n(r) d r}{\int_{0}^{\infty} \pi r^{2} n(r) d r}$

and

$v_{\text {eff }}=\frac{1}{\pi r^{2} r_{\text {eff }}^{2}} \int_{0}^{\infty}\left(r-r_{\text {eff }}\right)^{2} \pi r^{2} n(r) d r$. 

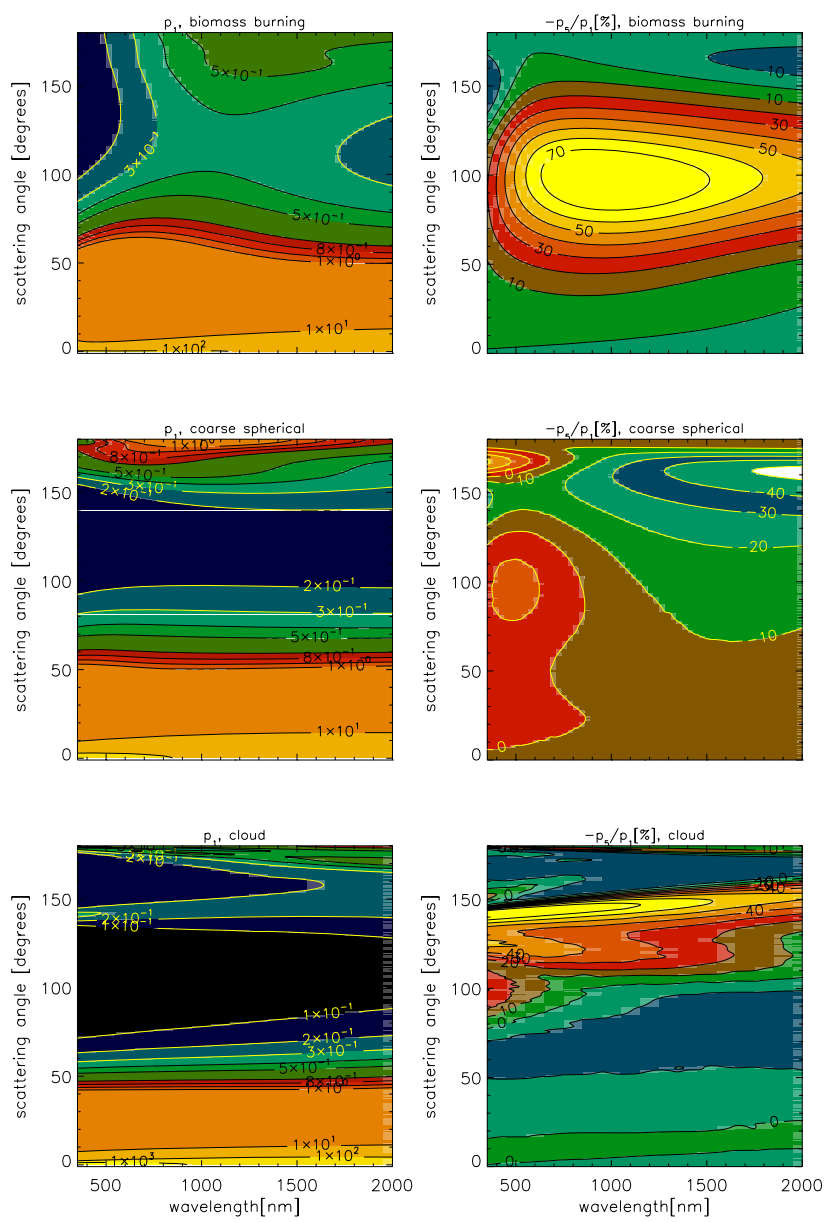

Fig. 1. Element $p_{1}$ (left panels) and signed degree of linear polarization $-p_{5} / p_{1}$ (right panels) of the scattering phase matrix as a function of wavelength and scattering angle for biomass burning aerosols (upper panels), coarse spherical aerosols (middle panels), and cloud particles (lower panel).

In what follows the superscripts $s$ and $l$ are used to refer to the small- and large mode of the size distribution, respectively. In addition to the $r_{\text {eff }}, v_{\text {eff }}$, and the column integrated aerosol number concentration of each mode, also the complex refractive index $m=m_{\mathrm{r}}+i m_{\mathrm{i}}$ is needed to characterize aerosols. In this paper it is assumed that the spectral dependence of the refractive index in the $350-2250 \mathrm{~nm}$ spectral range can be sufficiently described by a linear combination of the refractive index spectra of four aerosol types (mineral dust, sulfate, water-soluble, soot). The refractive indices for these types describe the most important spectral features of all types discussed by d'Almeida et al. (1991). Coefficients for the spectra of the real- and imaginary part of the refractive index are considered as unknown parameters. This means that per mode there are 8 unknown parameters related to refractive index ( 4 for the real part and 4 for the imaginary part). Thus, for a bimodal size distribution there are 22 microphysical aerosol fit parameters, i.e. 6 for the size distribution and 16 for the refractive index. Aerosol layer height is included as an additional fit parameter because fixing this parameter potentially results in biases of the retrieved other aerosol parameters. Here, it should be noted that by far the most accurate information on aerosol height distribution can be obtained from active sensors (Winker et al., 2009).

For retrieval simulations that involve clouds a homogeneous cloud layer is assumed with a cloud particle size distribution that is described by a mono-modal log-normal distribution. This leads to 3 additional unknown parameters: cloud effective radius, cloud effective variance and cloud droplet number concentration. It is assumed that information on cloud height is provided through external information, e.g. measurements in the thermal infrared or measurements in the Oxygen A absorption band. For retrievals in partly clouded scenes it is assumed that the intensity vector $\boldsymbol{I}$ of a partly cloudy scene can be described by the independent pixel approximation (which ignores 3-dimensional radiative transfer effects):

$\boldsymbol{I}=f \boldsymbol{I}_{\text {cloud }}+(1-f) \boldsymbol{I}_{\text {clear }}$,

where $f$ is the cloud fraction of the pixel, and $\boldsymbol{I}_{\text {cloud }}$ and $\boldsymbol{I}_{\text {clear }}$ are the intensity vector for a fully cloudy atmosphere and a clear atmosphere, respectively. So, for retrievals in partly cloudy scenes another parameter, the cloud fraction, is added to the retrieval problem.

To account for surface reflection in the retrieval simulations, the same approach is used as described by Hasekamp and Landgraf (2007). Here, the reflection matrix $\mathbf{R}_{s}$ of the surface is described by a Lambertian term $\mathbf{A}$ and a combination of 2 kernels $\mathbf{R}_{i}$ that describe the directional and polarization properties of the surface,

$\mathbf{R}_{s}\left(\lambda, \vartheta_{\text {in }}, \vartheta_{\text {out }}, \Delta \varphi\right)=\mathbf{A}(\lambda)+\sum_{i=1}^{2} f_{i} \mathbf{R}_{i}\left(\vartheta_{\text {in }}, \vartheta_{\text {out }}, \Delta \varphi\right)$

where $\vartheta_{\text {in }}$ and $\vartheta_{\text {out }}$ are the incoming and outgoing zenith angles, respectively, $\Delta \varphi$ is the relative azimuth angle, and the $f_{i}$ are coefficients for the two kernels, for which the model for bare soils of Bréon et al. (1995) and the vegetation model of Rondeaux and Herman (1991) are used. For both kernels the coefficients $f_{i}$ are included as unknown parameters in the retrieval. Additionally, the Lambertian term is included as an unknown parameter for each wavelength band at which a measurement is performed, unless explicitly stated otherwise.

\subsection{Forward model and inversion}

Let us now define a state vector $\boldsymbol{x}$ that contains the parameters to be retrieved. Furthermore, let us consider a measurement vector $\boldsymbol{y}$ that contains the measurements of the instrument type under consideration, e.g. multiple-wavelength multiple viewing-angle measurements of intensity and polarization. The retrieval of state vector $\boldsymbol{x}$ from measurement 
vector $\boldsymbol{y}$ requires a forward model $\mathbf{F}$ that describes how $\boldsymbol{y}$ and $\boldsymbol{x}$ are related,

$\boldsymbol{y}=\mathbf{F}(\boldsymbol{x})+\mathbf{e}_{y}$,

where $\mathbf{e}_{y}$ is an error term. The forward model consists of two parts. The first part relates the physical aerosol and cloud properties (size distribution, refractive index) to their optical properties (optical thickness, single scattering albedo, phase matrix). This relation can be described by Mie theory for spherical particles (van de Hulst, 1957) or alternative theories for particles with other shapes (see e.g. Dubovik et al., 2006; Kokhanovsky, 2003; Wiscombe and Grams, 1988; Koepke and Hess, 1988; Mishchenko and Travis, 1994; Mishchenko et al., 1995). In this paper only spherical aerosols are considered which allows the use of Mie theory. The second part of the forward model is an atmospheric radiative transfer model that simulates the intensity vector at the top of the atmosphere for given optical input parameters. Here, the vector radiative transfer model described by Hasekamp and Landgraf (2002); Hasekamp and Landgraf (2005a) is used, to model the transport of radiation in the atmosphere This model solves the radiative transfer equation using the GaussSeidel iterative method.

The aim of an inversion algorithm is to find a state vector $\hat{\boldsymbol{x}}$ for which forward model $\mathbf{F}(\hat{\boldsymbol{x}})$ and measurement $\boldsymbol{y}$ are in optimal agreement. Since the forward model is not linear in the unknown parameters the solution of the inversion problem has to be found iteratively. Here, for each iteration step $n$ the forward model in Eq. (10) is replaced by its linear approximation,

$\mathbf{F}\left(x_{n+1}\right) \approx \mathbf{F}\left(x_{\mathrm{n}}\right)+\mathbf{K}\left[x_{\mathrm{n}+1}-\boldsymbol{x}_{\mathrm{n}}\right]$

where $\boldsymbol{x}_{\mathrm{n}}$ is the state vector for the iteration step under consideration and $\mathbf{K}$ is the Jacobian matrix containing the derivatives of the forward model with respect to the elements of $\boldsymbol{x}_{n}$, where element $K_{i j}$ of $\mathbf{K}$ is defined by:

$K_{i j}=\frac{\partial F_{i}}{\partial \boldsymbol{x}_{j}}\left(\boldsymbol{x}_{\mathrm{n}}\right)$.

The Jacobian matrix is calculated in an analytical way, simultaneously with the intensity vector (Landgraf et al., 2001, 2002; Hasekamp and Landgraf, 2005a).

In this paper, two inversion methods are employed to retrieve the state vector $\boldsymbol{x}$ with unknown aerosol, cloud, and surface parameters from measurement vector $y$. Retrievals from Multi-angle photo-polarimetric measurements do not require a priori information and thus can be performed using the least squares method, that yield a retrieved state vector $\hat{\mathbf{x}}_{\text {lsq }}$ given by

$\hat{\mathbf{x}}_{\mathrm{lsq}}=\min _{\boldsymbol{x}}\left\|\mathbf{S}_{y}^{-\frac{1}{2}}(\mathbf{F}(\boldsymbol{x})-\boldsymbol{y})\right\|^{2}$.

Assuming a linear dependence of the forward model within the range of the measurement error, the Jacobian matrix $\mathbf{K}$ can be used to calculate the retrieval error covariance matrix $\mathbf{S}_{x}$ in the final iteration step:

$\mathbf{S}_{x}=\left(\mathbf{K}^{T} \mathbf{S}_{y}^{-1} \mathbf{K}\right)^{-1}$.

For comparisons that involve measurement types for which the retrieval represents an ill posed problem, the Phillips Tikhonov regularization method is used which introduces a side constraint in addition to the minimization of the least squares cost function:

$\hat{\mathbf{x}}_{\mathrm{reg}}=\min _{\boldsymbol{x}}\left(\left\|\mathbf{S}_{y}^{-\frac{1}{2}}(\mathbf{F}(\boldsymbol{x})-\tilde{\mathbf{y}})\right\|^{2}+\gamma\left\|\boldsymbol{\Gamma}\left(\boldsymbol{x}-\boldsymbol{x}_{a}\right)\right\|^{2}\right)$,

where $\boldsymbol{x}_{a}$ is an a priori state vector, $\mathbf{S}_{y}$ is the measurement error covariance matrix, $\boldsymbol{\Gamma}$ is a diagonal matrix that contains weighting factors for the different state vector elements in the side constraint, and the regularization parameter $\gamma$ balances the two minimizations in Eq. (15). An appropriate value for $\gamma$ is found using the L-curve (Hansen, 1992; Hansen and O'Leary, 1993). For applications of the L-curve method see e.g. the papers of Hasekamp and Landgraf (2001); Hasekamp and Landgraf (2005b); van Diedenhoven et al. (2007).

The state vector retrieved using Eq. (15) combines information retrieved from the measurement with a priori information:

$\hat{\mathbf{x}}_{\text {reg }}=\mathbf{A} \boldsymbol{x}_{\text {true }}+(\boldsymbol{I}-\mathbf{A}) \boldsymbol{x}_{a}+\mathbf{e}_{x}$,

where $\mathbf{A}$ is the averaging kernel (Rodgers, 2000), and $\mathbf{e}_{x}$ represents the error in the state vector caused by measurement and forward model errors.

For inversions based on Eq. (15), the covariance matrix $\mathbf{S}_{x}$ of the retrieved state vector is given by

$\mathbf{S}_{x}=\mathbf{S}_{\mathrm{r}}+\mathbf{S}_{\mathrm{e}}$,

where $\mathbf{S}_{\mathrm{r}}$ is the regularization error covariance matrix which describes the effect of the a priori error covariance matrix $\mathbf{S}_{\mathrm{a}}$ on $\mathbf{x}$,

$\mathbf{S}_{\mathrm{r}}=(\boldsymbol{I}-\mathbf{A}) \mathbf{S}_{\mathrm{a}}(\boldsymbol{I}-\mathbf{A})^{T}$,

and $\mathbf{S}_{\mathrm{e}}$ is the retrieval error covariance matrix that describes the effect of measurement- and forward model errors on $\boldsymbol{x}$,

$\mathbf{S}_{\mathrm{e}}=\mathbf{D} \mathbf{S}_{y} \mathbf{D}^{T}$,

where D is the contribution- or gain matrix (Rodgers, 2000).

For the investigation of retrieval errors using synthetic measurements, Eqs. (14) and (17) can be used without doing a full iterative retrieval. The retrieval errors given by $\mathbf{S}_{x}$ can be evaluated for any given measurement error covariance matrix $\mathbf{S}_{y}$. The validity of a linear error mapping procedure as used in this paper has been demonstrated by Hasekamp and Landgraf (2005a) for aerosol retrieval from synthetic GOME-2 measurements. The 1- $\sigma$ (standard deviation) errors on the different aerosol parameters are given by the square 
root of the diagonal elements of $\mathbf{S}_{x}$. Optical aerosol properties such as the Aerosol Optical Thickness (AOT) can be derived from the aerosol microphysical parameters contained in the state vector $\boldsymbol{x}$. The standard deviation $\sigma_{\tau}$ on the AOT can be obtained from the retrieval error covariance matrix $\mathbf{S}_{x}$ via

$\sigma_{\tau}=\sqrt{\sum_{i=1}^{N} \sum_{j=1}^{N} S_{i, j} \frac{\partial \tau}{\partial x_{i}} \frac{\partial \tau}{\partial x_{j}}}$

where $S_{i, j}$ denotes element $(\mathrm{i}, \mathrm{j})$ of $\mathbf{S}_{x}$. A similar expression holds for the single scattering albedo $\omega$.

\section{Capabilities of different measurement types under clear sky conditions}

In this section, the aerosol retrieval capabilities under clear sky conditions are compared for the following 5 generic measurement types:

1. Multiple-viewing-angle multiple-wavelength measurements of intensity and polarization.

2. Multiple-viewing-angle multiple wavelength measurements of only intensity.

3. Dual-viewing-angle multiple wavelength measurements of only intensity.

4. Single-viewing-angle measurements of intensity and polarization.

5. Single viewing-angle measurements of only intensity.

For the multiple-viewing-angle measurements 17 viewing angles are used between $-60^{\circ}-60^{\circ}$ (equally spaced). For the dual-view measurements viewing angles of $0^{\circ}$ and $60^{\circ}$ are used, whereas for the single-view measurements a viewing angle of $0^{\circ}$ (nadir) is used.

All simulations are performed for 10 wavelength bands with central wavelengths at: $350 \mathrm{~nm}, 440 \mathrm{~nm}, 530 \mathrm{~nm}$, $620 \mathrm{~nm}, 710 \mathrm{~nm}, 800 \mathrm{~nm}, 890 \mathrm{~nm}, 1600 \mathrm{~nm}$, and $2200 \mathrm{~nm}$. A Gaussian spectral response function with a Full Width at Half Maximum (FWHM) of $10 \mathrm{~nm}$ has been used. Concerning the instrument noise, a Signal to Noise Ratio (SNR) of 500 is assumed for a Lambertian equivalent reflectance of 0.4 . The noise for other elements of the measurement vector is related to this value assuming that the noise is proportional to the square root of the signal. In addition to the instrument noise a noise floor is added to account for biases in measurement and forward model. For the retrieval simulations relative Stokes parameters $q=Q / I$ and $u=U / I$ are used because they are less sensitive to calibration errors. The noise floor on the intensity is denoted as $e_{\text {int }}$ and referred to as the radiometric accuracy. The noise floor on Stokes fractions $q$ and $u$ is denoted as $e_{\mathrm{pol}}$ and referred to as the polarimetric accuracy.
The aerosol properties used for the retrieval simulations of this paper are shown in Table 1. Wavelength dependent properties such as optical thickness and refractive index are in this paper given for a wavelength of $550 \mathrm{~nm}$, unless explicitly stated otherwise. The surface reflection matrix is simulated for a scene covered for $50 \%$ by vegetation and $50 \%$ by soil. This means that the coefficients corresponding to the 2 kernels in Eq. (9) are both $\frac{1}{2}$. The Lambertian term in Eq. (9) is calculated using the albedos corresponding to "deciduous" and "Gray silty clay" of the ASTER Spectral Library.

The comparisons presented in this section involve measurement types for which the retrieval problem as formulated here is an ill-posed problem. Therefore, it is needed to incorporate a priori information in the retrieval process. The a priori information does not effect the amount of regularization since this is determined from the L-curve. However, for the calculation of the regularization error it is necessary to assume an a priori covariance matrix. For our simulations a diagonal a priori covariance matrix is assumed with $1 \sigma$-errors of $100 \%$ on the size distribution parameters and coefficients for the imaginary refractive index, $10 \%$ for the coefficients of the real refractive index, and $50 \%$ for the surface parameters.

\subsection{Comparison of single-view and multiple view mea- surement types}

For single-viewing-angle intensity measurements, the simultaneous retrieval of aerosol and surface parameters is not possible, because the measurements can be fitted perfectly by the surface albedo at each wavelength. Therefore, the comparison of multi-view measurements with single-view measurements is performed using fixed surface properties.

Figure 2 shows the comparison between measurement types 1-5 for the case with fixed surface properties. Errors are shown for the aerosol optical thickness and single scattering albedo at $550 \mathrm{~nm}$, the effective radius of both modes and the real part of the refractive index of both modes. The shaded areas indicate the accuracy requirements on aerosol parameters for climate research, formulated by Mishchenko et al. (2004). It can be seen that single-viewing angle intensity measurements yield even for this case large errors on the aerosol parameters, leading to errors $>0.1$ on the aerosol optical thickness. This means that retrievals from single-viewing-angle intensity measurements rely strongly on aerosol information on the aerosol microphysical properties. For accurate optical thickness retrievals from such measurements the a priori errors should be much smaller than the errors used in this study. This result basically confirms what can be found in the scientific literature (see e.g. Tanré et al., 1996; Mishchenko and Travis, 1997a; Hasekamp and Landgraf, 2007). Single-viewing angle measurements of intensity and polarization yield errors on the aerosol parameters that are a factor 2-4 smaller than those of single viewing intensity only measurements. However, the retrieval errors are in most cases still larger than the requirements. The dual-view 

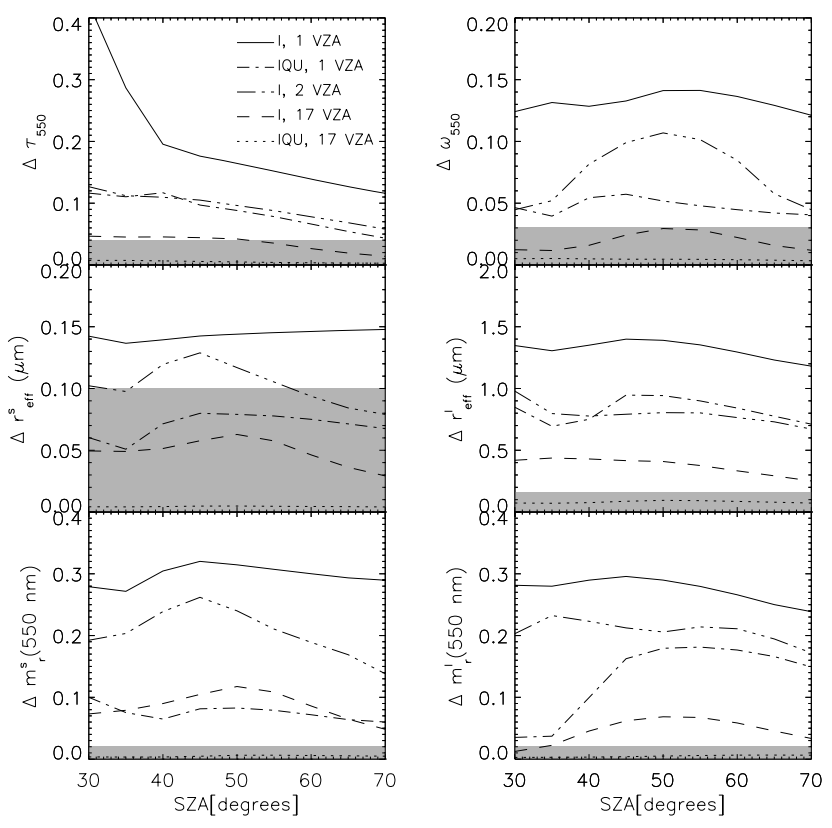

Fig. 2. Retrieval error on the aerosol optical thickness (upper left panel), single scattering albedo (upper right panel), fine mode effective radius (middle left panel), coarse mode effective radius (middle right panel), fine mode real refractive index (lower left panel), and coarse mode effective radius (lower right panel), as a function of Solar Zenith Angle (SZA), for different measurements types. For these retrievals it was assumed that the surface reflection properties are known. Retrieval simulations have been performed for relative azimuth angle $\Delta \varphi=0^{\circ}$. For the simulations a radiometric accuracy $e_{\text {int }}=2 \%$ and a polarimetric accuracy $e_{\mathrm{pol}}=0.002$ have been used, respectively. Simulations have been performed for the European Background aerosol type (see Table 1). For the surface, the coefficients corresponding to the 2 kernels in Eq. (9) are both $\frac{1}{2}$. The Lambertian term in Eq. (9) is calculated using the albedos corresponding to "deciduous" and "Gray silty clay" of the ASTER Spectral Library.

intensity retrievals yield similar retrieval errors as the single viewing intensity and polarization measurements. Multi (17) viewing angle intensity retrievals are about a factor 2-3 more accurate in AOT, leading to AOT errors within or just larger than the requirements. The errors on the refractive index are significantly larger than the requirement for this measurement type. The multiple-viewing-angle measurements of intensity and polarization meet the requirement for all aerosol parameters in this comparison.

It should be noted that for aerosol retrievals over land surfaces it is essential to accurately take into account the reflection properties of the Earth surface. MODIS retrievals use an empirical relationship between the albedo retrieved at the 2.1 micron band (where the aerosol contribution is small), and the albedo for the bands in the visible spectral range. OMI aerosol retrievals use external surface albedo information from satellite based climatologies. Uncertainties
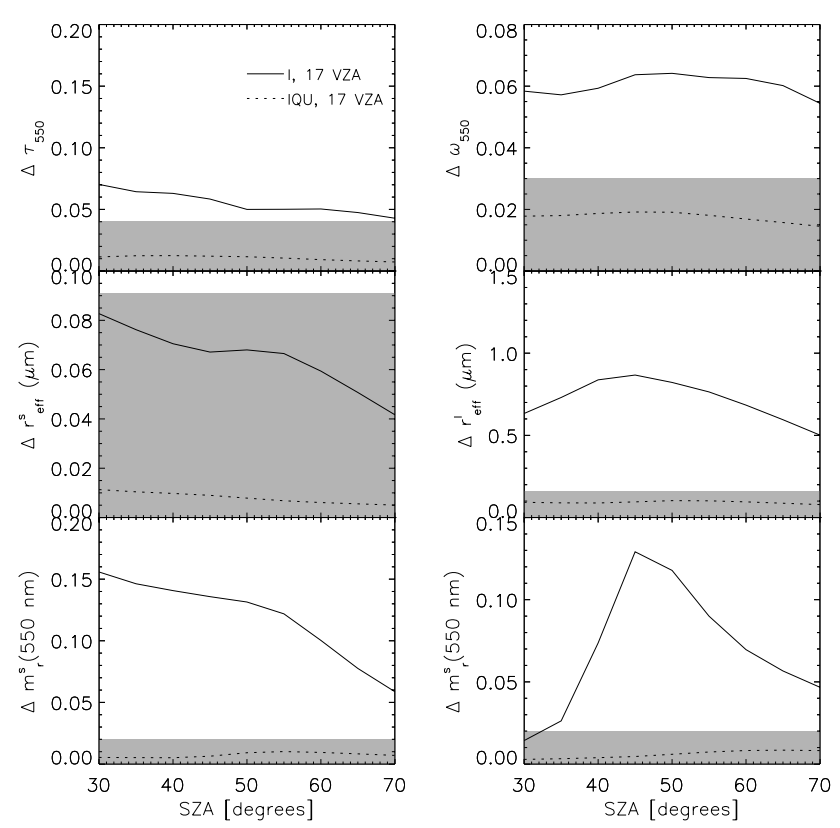

Fig. 3. As in Fig. 2, but for retrievals with unknown surface properties, and only considering multiple-viewing-angle measurements.

in the used surface albedos represent one of the largest error sources on retrieved aerosol properties from these instruments. By far the most accurate way to account for surface reflection is to simultaneously retrieve aerosol and surface properties.

\subsection{Comparison of multiple viewing measurement types}

Retrievals from Multiple-viewing-angle measurements can take advantage of the different angular reflectance signatures of the surface and the atmosphere to accomplish the retrieval of aerosol optical thickness over land surfaces. Figure $3 \mathrm{com}-$ pares retrieval errors from the multiple-viewing-angle measurement types for the simultaneous retrieval of aerosol and surface properties. This comparison has been performed for the European Background scenario with and Aerosol Optical Thickness (AOT) of 0.2 (at $550 \mathrm{~nm}$ ). It can be seen that for this case multi-view intensity only measurements produce AOT errors that are just larger than the requirement. For, the single scattering albedo, large mode effective radius, and refractive index the error are significantly larger than the requirements. This means that for this measurement type more accurate a priori information, than used in this study, is needed on aerosol and surface properties in order to meet the requirements. The multiple-viewing-angle measurements of intensity and polarization are by far most accurate with AOT errors below 0.015. Also the other aerosol parameters are much more accurately retrieved, and are able to meet the requirements. Clearly, an instrument dedicated to aerosol retrievals should provide multiple-viewing-angle measurements of intensity and polarization. 

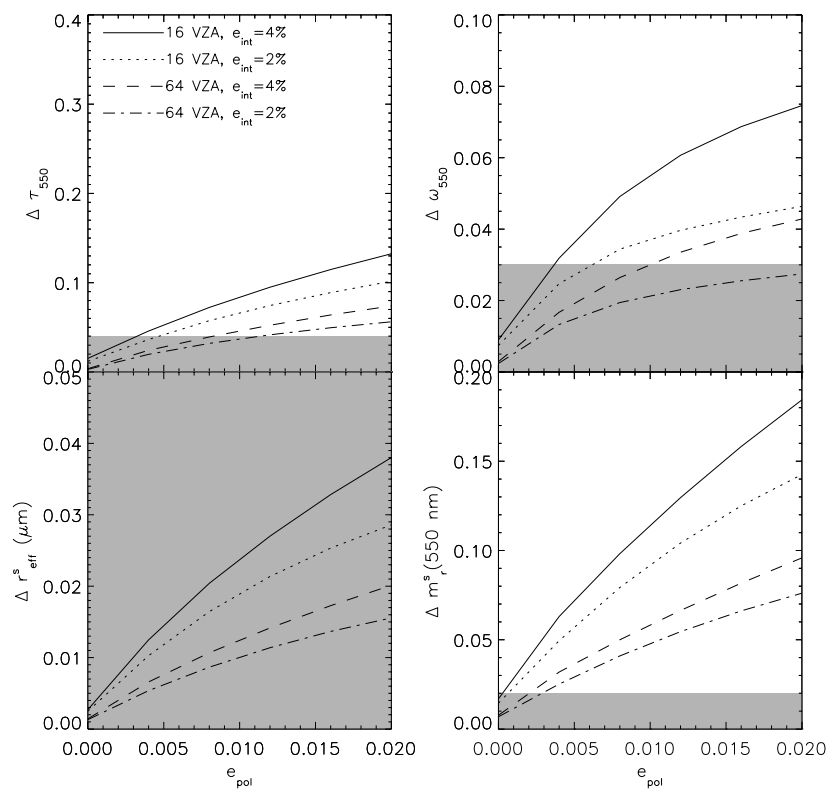

Fig. 4. Retrieval error on the aerosol optical thickness (upper left panel), single scattering albedo (upper right panel), fine mode effective radius (lower left panel), and fine mode real refractive index (lower right panel), as a function of polarimetric accuracy, for a situation with a biomass burning aerosol layer with $\mathrm{AOT}=0.5$ situated between $0-2 \mathrm{~km}$, below a partially clouded scene (cloud fraction $=0.1$ ) with a cloud layer between $2-3 \mathrm{~km}$. Simulations have been performed for a relative azimuth angle $\Delta \varphi=0^{\circ}$. Multi-angle photo-polarimetric measuremenst with respectively 16 and 64 viewing angles have been considered. Radiometric accuracies have been considered of respectively $2 \%$ and $4 \%$. Errors are assumed to be uncorrelated.

\section{Aerosol retrieval for cloudy scenes}

The results of the previous section, and those of Mishchenko and Travis (1997a) and Hasekamp and Landgraf (2007) demonstrate the capabilities of multi-angle photopolarimetric measurements under perfectly cloud free conditions. However, a very important problem related to aerosol retrieval is to perform an adequate cloud screening. Here on the one hand, if the cloud screening procedure is not strict enough the ground scene has the probability of residual cloud cover which causes large errors on the retrieved aerosol parameters. On the other hand, if the cloud screening procedure is too strict, too many clear sky cases will falsely be flagged cloudy, which may result in data gaps for areas with hydrated aerosols, the so called Twilight zone (Koren et al., 2007), and for other areas with high aerosol loading. The problems noted above become particularly relevant in regions close to clouds, where aerosol measurements are extremely important to understand the aerosol indirect effects. Also, aerosol measurements above clouds are important to understand the aerosol semi-direct effect. In this section the possibility is explored to perform a simultaneous retrieval of aerosol and
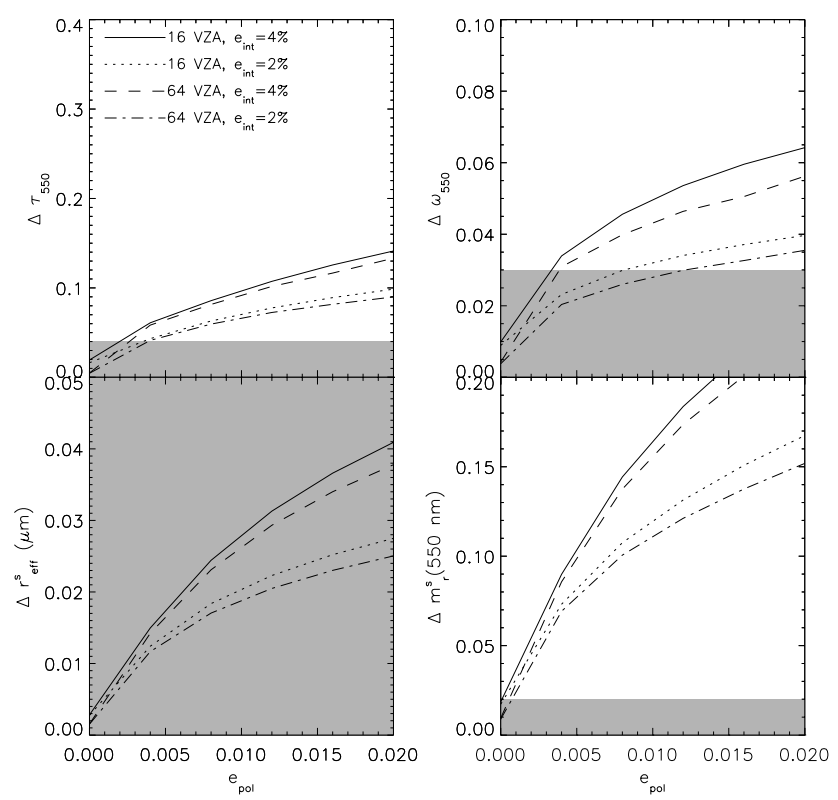

Fig. 5. Same as Fig. 4 but for errors that are correlated for different wavelengths and different viewing angles. Here, an exponentional decay is assumed of the correlation with wavelength and viewing angle, where the correlation is reduced to $1 / e$ for wavelength differences of $100 \mathrm{~nm}$ and viewing angle differences of $60^{\circ}$.

cloud properties for partly cloudy scenes and for fully cloudy scenes where the aerosol layer is located above the cloud.

\subsection{Partly cloudy scenes}

Retrieval simulations have been performed for partly cloudy atmospheres with a liquid water cloud located in a homogeneous layer between $2-3 \mathrm{~km}$ and a biomass burning aerosol located below the cloud. Compared to the state vector for the clear sky retrievals of the previous sections, the state vector of this retrieval problem consists additionally of the following 4 cloud parameters: cloud effective radius, cloud effective variance, cloud droplet number concentration, and cloud fraction. It is assumed that information on cloud height is provided through external information, e.g. measurements in the thermal infrared or measurements in the Oxygen A absorption band.

Figures 4 and 5 shows the retrieval error on the aerosol optical thickness, single scattering albedo, small mode effective radius, and small mode real part of refractive index, as a function of polarimetric accuracy, for radiometric accuracies of $2 \%$ and $4 \%$, respectively. Simulations have been performed for a cloud fraction $f=0.1$. Since the Biomass Burning aerosol type is dominated by the small mode, the large mode only has a small contribution to the total aerosol optical thickness. This implies that the microphysical properties of the large mode cannot be retrieved accurately, but also that for this case these parameters are of minor importance. 
Therefore, only results for microphysical properties of the small mode are shown here. Results are shown for measurement type 1 described in Sect. 4, and also for the same measurement types but with 64 viewing angles instead of 16 . Again, the shaded areas indicate the requirements as formulated by Mishchenko et al. (2004). Figure 4 corresponds to the case that the errors represented by $e_{\text {int }}$ and $e_{\mathrm{pol}}$ are uncorrelated, whereas Fig. 5 corresponds to the case that errors are correlated for different wavelengths and different viewing angles. Here, an exponentional decay is assumed of the correlation between different wavelengths and different viewing angles, where the correlation is reduced to $1 / e$ for wavelength differences of $100 \mathrm{~nm}$ and viewing angle differences of $60^{\circ}$. From Figs. 4 and 5 it follows that multi-angle photo-polarimetric measurements indeed have the capability to distinguish between aerosols and clouds. For the case with uncorrelated errors, the measurement type with 16 viewing angles allows to meet the required accuracy on optical thickness, single scattering albedo, and fine mode effective radius if the polarimetric accuracy is better than about 0.005 and the radiometric accuracy is $2 \%$. If the radiometric accuracy is $4 \%$, a polarimetric accuracy of better than 0.003 is needed to meet the requirements on the same parameters. For the case with correlated errors, the requirements on optical thickness, single scattering albedo, and fine mode effective radius are met if the polarimetric accuracy is better than about 0.003 and the radiometric accuracy is $2 \%$. If the radiometric accuracy is reduced to $4 \%$ a polarimetric accuracy of 0.002 is needed to meet the requirements on these parameters. The requirement on the fine mode refractive index is not met for the 16 viewing angle measurements type, except for the unrealistic case that $e_{\text {pol }}=0$ (i.e. the only error on $q$ and $u$ is measurement noise).

If the number of viewing angles is increased from 16 to 64 the retrieval errors on all parameters decrease significantly for the case with uncorrelated errors, but not for the case with correlated errors. This can be explained by the fact that for uncorrelated errors increasing the number of measurements effectively increases the Signal to Noise Ratio (SNR). For correlated errors this is not the case, since they represent broad spectral and angular structures. In this case improving polarimetric and radiometric accuracy leads to a larger error reduction for the aerosol parameters than an increase of the number of viewing angles. Overall, the retrieval simulations of Figs. 4 and 5 confirm the importance of highly accurate polarimetric measurements, as was already known for clear sky retrievals (Mishchenko and Travis, 1997a; Hasekamp and Landgraf, 2007; Waquet et al., 2009a).

Figure 6 shows the same retrieval errors as in Figs. 4 and 5, but now as a function of cloud fraction. For these simulations a radiometric accuracy of $2 \%$ and a polarimetric accuracy of 0.002 were used, for both uncorrelated and correlated errors. The measurement type with 16 viewing angles allows to retrieve optical thickness and single scattering albedo with the required accuracy for cloud fractions $<0.25$. A similar cloud
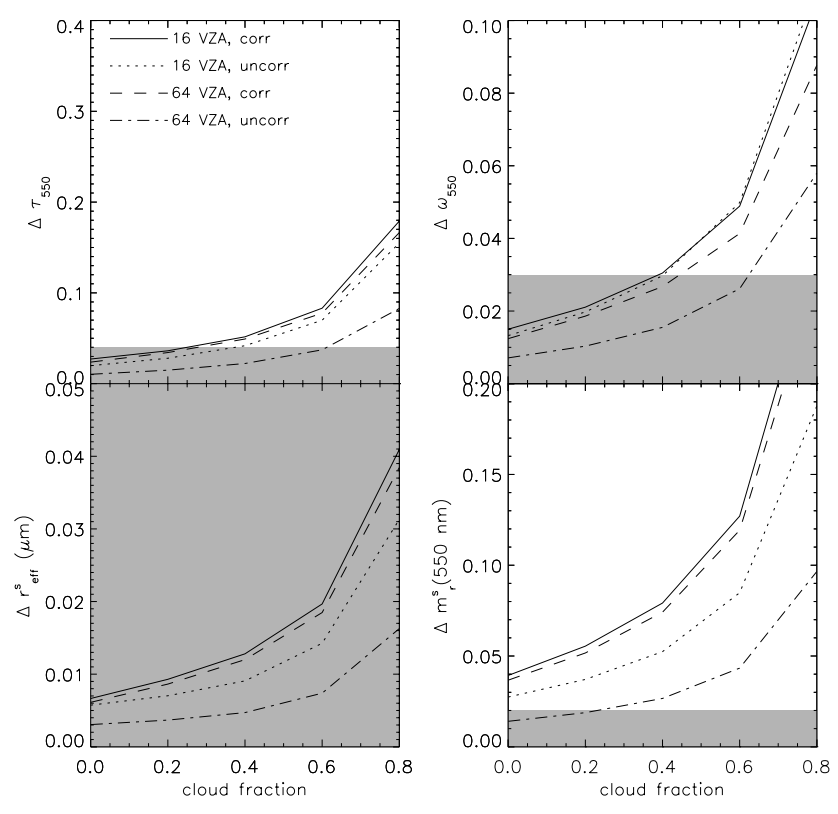

Fig. 6. Retrieval error on the aerosol optical thickness (upper left panel), single scattering albedo (upper right panel), fine mode effective radius (lower left panel), fine mode real refractive index (lower right panel), as a function of cloud fraction for a situation with a biomass burning aerosol layer with AOT $=0.5$ situated between 0 $2 \mathrm{~km}$, below a partially clouded scene with a cloud layer between 2$3 \mathrm{~km}$. Simulations have been performed for a relative azimuth angle $\Delta \varphi=0^{\circ}$. Multi-angle photo-polarimetric measuremenst have been considered with respectively 16 and 64 viewing angles, and with a polarimetric accuracy of 0.002 and a radiometric accuracy of $2 \%$. Both uncorrelated and correlated errors have been considered.

fraction threshold applies to the 64 viewing angle measurement type with correlated errors, whereas if the errors are uncorrelated this value relaxes to 0.6 . The effective radius of the small mode can even be retrieved for larger cloud fractions. The requirement on the refractive index is not met for the 16 viewing angles measurement type, and neither for 64 viewing angle measurement type in case of correlated errors. Only for the 64 viewing angle measurement type with uncorrelated errors the requirement on the refractive index is met for cloud fractions $<0.20$. The differences in accuracy of the refractive index between Fig. 6 for $f=0$, and Fig. 3 can be explained by the fact that the retrievals of Fig. 6 also have cloud properties as fit parameters. Furthermore, the biomass burning aerosol type used for Fig. 6 has a much smaller fine mode effective radius than the European Background aerosol model used in Fig. 3, and for small particles it is harder to retrieve the refractive index (Miecznik et al., 2005).

\subsection{Aerosol retrieval over uniform cloud cover}

It has been demonstrated by Waquet et al. (2009b) that the multi-angle photo-polarimetric measurements of POLDER/PARASOL allow to retrieve aerosol optical 

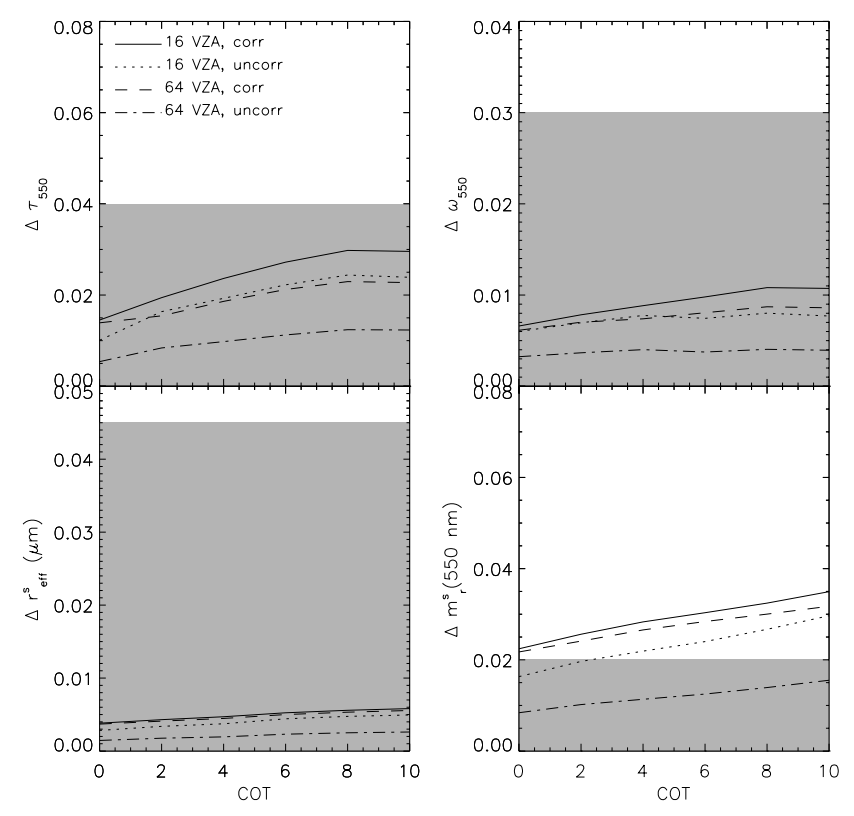

Fig. 7. Retrieval error on the aerosol optical thickness (upper left panel), single scattering albedo (upper right panel), fine mode effective radius (middle left panel), coarse mode effective radius (middle right panel), fine mode real refractive index (lower left panel), and coarse mode effective radius (lower right panel), as a function of cloud optical thickness (COT) for a situation with a biomass burning aerosol layer with AOT $=0.5$ situated between $4-6 \mathrm{~km}$ over a fully cloudy scene with a cloud layer between $2-3 \mathrm{~km}$. Simulations have been performed for multi-angle photo-polarimetric measuremenst with respectively 16 and 160 viewing angles. Polarimetric accuracies of 0.002 and 0.005 have been considered and a radiometric accuracy of $2 \%$.

thickness and size for situations with an aerosol layer located above a uniform cloud deck. In the current study, the possibility is investigated to extend the retrieval of Waquet et al. (2009b) to the retrieval of all aerosol parameters of a bi-modal aerosol model and to retrieve additionally the properties of the underlying cloud (effective radius, effective variance, droplet number concentrations). Retrieval simulations have been performed for fully cloudy atmospheres with a liquid water cloud located in a homogeneous layer between $2-3 \mathrm{~km}$ and a biomass burning aerosol located in a layer between 4-6 km.

Figure 7 shows the retrieval error on the aerosol optical thickness, single scattering albedo, small mode effective radius, and small mode real part of the refractive index as a function of cloud optical thickness. For these simulations a radiometric accuracy of $2 \%$ and polarimetric accuracies of 0.002 have been used, where both correlated and uncorrelated errors have been considered. Overall, the retrieval errors on all parameters are significantly smaller for this scenario than for the scenario with an aerosol layer below a partly cloudy scene. Clearly, the reason for this is that for the latter situation part of the aerosol signal is shielded by the cloud and that one additional cloud parameter (i.e. the cloud fraction) needs to be retrieved.

It follows from Fig. 7 that the retrieval errors on the aerosol optical thickness, single scattering albedo, and small mode effective radius are well below the requirements for both the 16 viewing-angle and 64 viewing-angle measurement types. The dependence of the retrieval errors for these 3 parameters on cloud optical thickness (COT) is small for COT $>6$. As for the situation with an aerosol layer below a partly cloudy scene, it is also difficult to retrieve the refractive index with the required accuracy for an aerosol layer over a uniform cloud field. In fact, the requirement is only met in case of uncorrelated errors, indicating large sensitivity to systematic calibration errors.

\section{Conclusions}

In this paper, the possibilities have been explored to simultaneously retrieve aerosol and cloud properties from multiangle photo-polarimetric measurements. Furthermore, for clear sky conditions a review has been given of the capabilities of multi-angle photopolarimetric measurements in comparison to other instrument types, demonstrating that already for clear sky conditions polarization measurements are highly important for the retrieval of aerosol optical and microphysical properties over land surfaces with unknown reflection properties.

An approach for the simultaneous retrieval of aerosol and cloud properties in partly clouded scenes would circumvent the important problems that aerosol retrieval schemes have with cloud screening, especially in areas in the neighborhood of clouds. Furthermore, aerosol measurements above clouds are needed to estimate the aerosol semi-direct effect. Retrieval simulations point out that multi-angle photopolarimetric measurements indeed have the capability to distinguish between aerosols and clouds. Namely, in addition to all aerosol parameters of a bi-modal aerosol model, also cloud effective radius, effective variance, droplet number concentration, and cloud fraction can be retrieved. Polarimetric measurements with high accuracy (0.002-0.004) play an important role here. Such accuracies are expected from the new generation of photo-polarimetric satellite instruments, such as APS and the Multiangle SpectroPolarimetric Imager (MSPI, Diner et al., 2007, 2010).

For the simultaneous retrieval of aerosol and cloud properties the effect of increasing the number of viewing angles has been investigated. It was found that if the number of viewing angles is increased from 16 to 64 the retrieval accuracies on the aerosol parameters only improve substantially if the photometric and polarimetric measurement errors are not correlated for different wavelengths and different viewing angles. This means that the improvement is mainly caused by an increased effective Signal to Noise Ratio (SNR). Nevertheless, having an instrument with more viewing angles would 
provide more flexibility in selecting certain angular ranges in the retrieval.

The simultaneous retrieval of aerosol and cloud properties for an elevated aerosol layer over a uniform cloud deck results in smaller retrieval errors on the aerosol parameters than for the situation that the aerosols are located below a broken cloud field. Clearly, the reason for this is that for the latter situation part of the aerosol signal is shielded by the cloud and that one additional cloud parameter (i.e. the cloud fraction) needs to be retrieved. In this case, the optical thickness, single scattering albedo, and fine mode effective radius can be retrieved with the required accuracy using 16 viewing angles.

For both the situation of an aerosol layer below a broken cloud field, as well as for an elevated layer above a homogeneous cloud field, it is difficult to retrieve the real part of the refractive index with an accuracy of 0.02 , which is the requirement set by Mishchenko et al. (2004). In fact, the retrieval error on this parameter is more often in the range $0.03-0.05$. It should be subject of future work to evaluate if such accuracies of the real part of the refractive index are still valuable for identifying aerosol chemical composition.

It is important to note that the results of this paper are obtained using a plane-parallel radiative transfer model, i.e. 3dimensional effects are ignored. Several studies suggest that 3-dimensional radiation transfer effects are important when doing cloud retrievals in broken cloud fields (Gabriel et al., 2009; Evans et al., 2008), or when doing aerosol retrievals in the adjacency of clouds (Marshak et al., 2008). In particular, it is suggested that in the latter case aerosol retrievals are affected by an apparent "bluing" effect, because light scattered by adjacent clouds is Rayleigh scattered in the direction of the satellite. This aerosol "bluing" effect is not yet confirmed by experiments (Redemann et al., 2009). Since the results of this paper are based on 1-dimensional radiative transfer calculations, they should be considered as a lower limit for the retrieval errors. It may be expected that 3-dimensional radiative transfer effects become important for cloud fractions above a certain threshold. In that respect, it is likely that the maximum cloud fractions for which certain accuracy requirements are met, as derived in this paper, are too optimistic. When interpreting simultaneous aerosol-cloud retrievals from real measurements, it is important to now these thresholds. Nevertheless, despite the simplified radiative transfer approach, the results of this paper demonstrate the great potential that multi-angle photo-polarimetric measurements have to distinguish between aerosols and residual cloud fraction. Moreover, it is important to note that polarized radiances are likely to be less affected by 3-dimensional radiative transfer effects than total radiances, because the polarized radiance signal mainly originates from single scattering.
Acknowledgements. The surface albedo spectra are reproduced from the ASTER Spectral Library through the courtesy of the Jet Propulsion Laboratory, California Institute of Technology, Pasadena, California. Copyright 1999, California Institute of Technology. ECHAM5-HAM model output has been provided by Gerrit de Leeuw, Finnish Meteorological Institute (FMI).

Edited by: A. A. Kokhanovsky

\section{References}

Albrecht, B. A.: Aerosols, Cloud Microphysics, and Fractional Cloudiness, Science, 245, 1227-1230, doi:10.1126/science.245. 4923.1227, 1989.

Andreae, M., Jones, C., and Cox, P.: Strong present-day aerosol cooling implies a hot future, Nature, 435, 1187-1190, 2005.

Bréon, F., Tanré, D., and Generoso, S.: Aerosol Effect on Cloud Droplet Size Monitored from Satellite, Science, 295, 834-838, doi:10.1126/science.1066434, 2002.

Bréon, F. M., Tanré, D., Lecomte, P., and Herman, M.: Polarized reflectance of bare soils and vegetation: Measurements and models, IEEE T. Geosci. Remote, 33, 487-499, 1995.

Chandrasekhar, S.: Radiative transfer, Dover Publications, Inc., New York, 1960.

Chowdhary, J., Cairns, B., Mishchenko, M., and Travis, L.: Retrieval of aerosol properties over the ocean using multispectral and multiangle photopolarimetric measurements from the Research Scanning Polarimeter, Geophys. Res. Lett., 28, 243-246, 2001.

Chowdhary, J., Cairns, B., and Travis, L.: Case studies of aerosol retrieval over the ocean from multiangle, multispectral photopolarimetric remote sensing data, J. Atmos. Sci., 59(3), 383-397, 2002.

Chowdhary, J., Cairns, B., Mishchenko, M., Hobbs, P., Cota, G., Redemann, J., Rutledge, K., Holben, B., and Russel, E.: Retrieval of aerosol scattering and absorption properties from photo-polarimetric observations over the ocean during the CLAMS experiment, J. Atmos. Sci., 62(4), 1093-1117, 2005.

d'Almeida, G., Koepke, P., and Shettle, E.: Atmospheric Aerosols: Global Climatology and Radiative Characteristics, A. Deepak Publishing, Hampton, VA, ISA, 1991.

Deuzé, J. L., Goloub, P., Herman, M., Marchand, A., Perry, G., Susana, S., and Tanré, D.: Estimate of the aerosol properties over the ocean with POLDER, J. Geophys. Res., 105, 15329-15346, 2000.

Deuzé, J. L., Bréon, F. M., Devaux, C., Goloub, P., Herman, M., Lafrance, B., Maignan, F., Marchand, A., Nadal, F., Perry, G., and Tanré, D.: Remote sensing of aerosols over land surfaces from POLDER-ADEOS-1 polarized measurements, J. Geophys. Res., 106, 4913-4926, 2001.

Diner, D., Martonchik, J., Kahn, R., Pinty, B., Gobron, N., Nelson, D., and Holben, B.: Using angular and spectral shape similarity constraints to improve MISR aerosol and surface retrievals over land, Remote Sens. Environ., 94, 155-171, 2005.

Diner, D. J., Davis, A., Hancock, B., Gutt, G., Chipman, R. A., and Cairns, B.: Dual-photoelastic-modulator-based polarimetric imaging concept for aerosol remote sensing, Appl. Optics, 46, 8428-8445, doi:10.1364/AO.46.008428, 2007. 
Diner, D. J., Ab Davis, B. H., Geier, S., Rheingans, B., Jovanovic, V., Bull, M., Rider, D. M., Chipman, R. A., Mahler, A.-B., and McClain, S. C.: First results from a dual photoelastic-modulatorbased polarimetric camera, Appl. Optics, 49, 2929-2946, 2010.

Dubovik, O., Sinyuk, A., Lapyonok, T., Holben, B. N., Mishchenko, M., Yang, P., Eck, T. F., Volten, H., Muñoz, O., Veihelmann, B., van der Zande, W. J., Leon, J., Sorokin, M., and Slutsker, I.: Application of spheroid models to account for aerosol particle nonsphericity in remote sensing of desert dust, J. Geophys. Res.-Atmos., 111, D11208, doi:10.1029/ 2005JD006619, 2006.

Evans, K. F., Marshak, A., and Várnai, T. The Potential for Improved Boundary Layer Cloud Optical Depth Retrievals from the Multiple Directions of MISR, J. Atmos. Sci., 65, 3179, doi: 10.1175/2008JAS2627.1, 2008

Gabriel, P., Barker, H. W., O’Brien, D., Ferlay, N., and Stephens, G. L.: Statistical approaches to error identification for planeparallel retrievals of optical and microphysical properties of three-dimensional clouds: Bayesian inference, J. Geophys. Res. (Atmospheres), 114, 6207, doi:10.1029/2008JD011005, 2009.

Hansen, J. E. and Travis, L. D.: Light scattering in planetary atmospheres, Space Sci. Rev., 16, 527-610, 1974.

Hansen, P.: Analysis of discrete ill posed problems by means of the L-curve, SIAM Rev., 34, 561-580, 1992.

Hansen, P. and O'Leary, D.: The use of the L-curve in the regularization of discrete ill posed problems, SIAM J. Sci. Comput., 14, 1487-1503, 1993.

Hasekamp, O. and Landgraf, J.: Ozone profile retrieval from backscattered ultraviolet radiances: The inverse problem solved by regularization, J. Geophys. Res.-Atmos., 106, 8077-8088, 2001.

Hasekamp, O. and Landgraf, J.: A linearized vector radiative transfer model for atmospheric trace gas retrieval, J. Quant. Spectrosc. Ra., 75, 221-238, 2002.

Hasekamp, O. P. and Landgraf, J.: Linearization of vector radiative transfer with respect to aerosol properties and its use in satellite remote sensing, J. Geophys. Res.-Atmos., 110, D04203, doi:10.1029/2004JD005260, 2005.

Hasekamp, O. P. and Landgraf, J.: Retrieval of aerosol properties over the ocean from multispectral single-viewing-angle measurements of intensity and polarization: Retrieval approach, information content, and sensitivity study, J. Geophys. Res.-Atmos., 110, 20207, doi:10.1029/2005JD006212, 2005.

Hasekamp, O. P. and Landgraf, J.: Retrieval of aerosol properties over land surfaces: capabilities of multiple-viewing-angle intensity and polarization measurements, Appl. Optics, 46, 33323344, doi:10.1364/AO.46.003332, 2007.

Herman, M., Deuzé, J.-L., Marchand, A., Roger, B., and Lallart, P.: Aerosol remote sensing from POLDER/ADEOS over the ocean: Improved retrieval using a nonspherical particle model, J. Geophys. Res.-Atmos., 110, D10S02, doi:10.1029/2004JD004798, 2005.

Koepke, P. and Hess, M.: Scattering functions of tropospheric aerosols: The effect of nonspherical particles, Appl. Optics, 27, 2422-2430, 1988.

Kokhanovsky, A. A.: Optical properties of irregularly shaped particles, J. Phys. D Appl. Phys., 36, 915-923, 2003.

Koren, I., Kaufman, Y., Remer, L., and Martins, J.: Measurements of the effect of Amazon smoke aerosol on in- hibition of cloud formation , Science, 303, 1342-1345, doi:10.1126/science.1089424, 2004.

Koren, I., Remer, L. A., Kaufman, Y. J., Rudich, Y., and Martins, J. V.: On the twilight zone between clouds and aerosols, Geophys. Res. Lett., 34, L08805, doi:10.1029/2007GL029253, 2007.

Kotchenruther, R. A., Hobbs, P. V., and Hegg, D. A.: Humidification factors for atmospheric aerosols off the mid-Atlantic coast of the United States, J. Geophys. Res., 104, 2239-2252, doi: 10.1029/98JD01751, 1999.

Landgraf, J., Hasekamp, O., Trautmann, T., and Box, M.:A linearized radiative transfer model for ozone profile retrieval using the analytical forward-adjoint perturbation theory, J. Geophys. Res., 106, 27291-27306, 2001.

Landgraf, J., Hasekamp, O., and Trautmann, T.: Linearization of radiative transfer with respect to surface properties, J. Quant. Spectrosc. Radiat. Transfer, 72, 327-339, 2002.

Lohmann, U. and Feichter, J.: Global indirect aerosol effects: a review, Atmos. Chem. Phys., 5, 715-737, doi:10.5194/acp-5-7152005, 2005.

Marshak, A., Wen, G., Coakley, J. A., Remer, L. A., Loeb, N. G., and Cahalan, R. F.: A simple model for the cloud adjacency effect and the apparent bluing of aerosols near clouds, J. Geophys. Res. (Atmospheres), 113, 14, doi:10.1029/2007JD009196,2008.

Miecznik, G., Illing, R., Petroy, S., and Sokolik, I. N.: Sensitivity metric approach for retrieval of aerosol properties from multiangular and multispectral polarized radiances, Appl. Optics, 44, 4186-4204, 2005.

Mishchenko, M. and Travis, L.: Light scattering by polydispersions of randomly oriented spheroids with sizes comparable to wavelengths of observation, Appl. Optics, 33, 7206-7225, 1994.

Mishchenko, M., Geogdzhayev, I., Cairns, B., Rossow, W., and Lacis, A.: Aerosol retrievals over the ocean by use of channels 1 and 2 AVHRR data: sensitivity analysis and preliminary results, Appl. Optics, 36, 7325-7341, 1999.

Mishchenko, M., Travis, L., and Lacis, A.: Multiple scattering of light by particles: Radiative transfer and coherent backscattering, Cambridge Univ. Press, Cambride, United Kingdom, 2006.

Mishchenko, M. I. and Travis, L. D.: Satellite retrieval of aerosol properties over the ocean using polarization as well as intensity of reflected sunlight, J. Geophys. Res., 102, 16989-17013, 1997a.

Mishchenko, M. I. and Travis, L. D.: Satellite retrieval of aerosol properties over the ocean using measurements of reflected sunlight, J. Geophys. Res., 102, 13543-13553, 1997 b.

Mishchenko, M. I., Lacis, A. A., Carlson, B., and Travis, L.: Nonsphericity of dust-like tropospheric aerosols: Implications for aerosol remote sensing and climate modeling, Geophys. Res. Lett., 22, 1077-1980, 1995.

Mishchenko, M. I., Cairns, B., Hansen, J. E., Travis, L. D., Burg, R., Kaufman, Y. J., Vanderlei Martins, J., and Shettle, E. P.: Monitoring of aerosol forcing of climate from space: analysis of measurement requirements, J. Quant. Spectrosc. Ra., 88, 149-161, 2004.

Quaas, J. and Boucher, O.: Constraining the first aerosol indirect radiative forcing in the LMDZ GCM using POLDER and MODIS satellite data, Geophys. Res. Lett., 32, L17814, doi: 10.1029/2005GL023850, 2005.

Quaas, J., Boucher, O., Bellouin, N., and Kinne, S.: Satellite-based estimate of the direct and indirect aerosol climate forcing, J. Geo- 
phys. Res.-Atmos., 113, D05204, doi:10.1029/2007JD008962, 2008.

Redemann, J., Zhang, Q., Russell, P. B., Livingston, J. M., and Remer, L. A.: Case studies of aerosol remote sensing in the vicinity of clouds, J. Geophys. Res. (Atmospheres), 114, 6209, doi: 10.1029/2008JD010774,2009

Remer, L. A., Kaufman, Y. J., Tanré, D., Mattoo, S., Chu, D. A., Martins, J. V., Li, R., Ichoku, C., Levy, R. C., Kleidman, R. G., Eck, T. F., Vermote, E., and Holben, B. N.: The MODIS Aerosol Algorithm, Products, and Validation., J. Atmos. Sci., 62, 947973, doi:10.1175/JAS3385.1, 2005.

Rodgers, C.: Inverse methods for Atmospheric Sounding: Theory and Practice, World Sc., River Edge, N. J., 2000.

Rondeaux, G. and Herman, M.: Polarization of light reflected by crop canopies, Remote Sens. Environ., 41, 227-237, 1991.

Solomon, S. (Ed.): Climate Change 2007: The Physical Science Basis, Contribution of Working Group (WG) 1 to the Fourth Assessment Report of the Intenational Panel on Climate Change (IPCC) (AR4), Cambridge Univ. Press., New York, 2007.

Stier, P., Feichter, J., Kinne, S., Kloster, S., Vignati, E., Wilson, J., Ganzeveld, L., Tegen, I., Werner, M., Balkanski, Y., Schulz, M., Boucher, O., Minikin, A., and Petzold, A.: The aerosolclimate model ECHAM5-HAM, Atmos. Chem. Phys., 5, 11251156, doi:10.5194/acp-5-1125-2005, 2005.

Tanré, D., Herman, M., and Kaufman, Y. J.: Information on aerosol size distribution contained in solar reflected spectral radiances, J. Geophys. Res., 101, 19043-19060, doi:10.1029/96JD00333, 1996.

Tanré, D., Kaufman, Y., Herman, M., and Mattoo, S.: Remote sensing of aerosol properties over the ocean using the MODIS/EOS spectral radiances, J. Geophys. Res., 102, 16971-16988, 1999.
Torres, O., Decae, R., Veefkind, P., and de Leeuw, G.: OMI aerosol retrieval algorithm, ATBD-OMI-03, 47-69, 2001.

Twomey, S.: The nuclei of natural cloud formation part I: The chemical diffusion method and its application to atmospheric nuclei, Pure Appl. Geophys., 43, 227-242, doi:10.1007/ BF01993559, 1959.

van de Hulst, H. C.: Light scattering by small particles, J. Wiley and sons, New York, 1957.

Van Diedenhoven, B., Hasekamp, O.P., and Landgraf, J.: Retrieval of cloud parameters from satellite-based reflectance measurements in the ultraviolet and the oxygen A-band, J. Geophys. Res., 112, D15208, doi:10.1029/2006JD008155, 2007.

Veefkind, J., de Leeuw, G., Stammes, P., and Koelemeijer, R.: Regional distribution of aerosols over land derived from ATSR-2 and GOME, Remote Sens. Environ., 74, 377-386, 2000.

Waquet, F., Cairns, B., Knobelspiesse, K., Chowdhary, J., Travis, L. D., Schmid, B., and Mishchenko, M. I.: Polarimetric remote sensing of aerosols over land, J. Geophys. Res.-Atmos., 114, D01206, doi:10.1029/2008JD010619, 2009a.

Waquet, F., Riedi, J., Labonnote, L. C., Goloub, P., Cairns, B., Deuzé, J., and Tanré, D.: Aerosol Remote Sensing over Clouds Using A-Train Observations, J. Atmos. Sci., 66, 2468-2480, doi: 10.1175/2009JAS3026.1, 2009b.

Winker, D. M., Vaughan, M. A., Omar, A., Hu, Y., Powell, K. A., Liu, Z., Hunt, W. H., \& Young, S. A.: Overview of the CALIPSO Mission and CALIOP Data Processing Algorithms, J. Atmos. Oceanic Technol., 26, 2310, doi:10.1175/2009JTECHA1281.1, 2009.

Wiscombe, W. and Grams, G.: Scattering from nonspherical Chebyshev particles,2, Means of angular scattering patterns., Appl. Optics, 27, 2405-2421, 1988. 